\title{
PROPOSTA DE UTILIZAÇÃO DE TECNOLOGIAS DE IMPRESSÃO 3D PARA O ENSINO DE CARTOGRAFIA E GEOMORFOLOGIA
}

\author{
Hanna Aimée da Fraga Gonçalves ${ }^{(a)}$, Érika Medina de Medeiros ${ }^{(\mathrm{b})}$, Gustavo Mota de Sousa ${ }^{(\mathrm{c})}$, \\ Delson Lima Filho ${ }^{(\mathrm{d})}$
}

(a) Departamento de Engenharia de Agrimensura e Cartográfica, Universidade Federal Rural do Rio de Janeiro, hannaaimeefg@hotmail.com.

(b) Departamento de Geociências, Universidade Federal Rural do Rio de Janeiro, medeiroserika96@gmail.com.

(c) Departamento de Geociências, Universidade Federal Rural do Rio de Janeiro, gustavobond@gmail.com.

(d) Departamento de Arquitetura e Urbanismo, Universidade Federal Rural do Rio de Janeiro, limafilho.delson@gmail.com.

\section{EIXO: GEOGRAFIA FÍSICA: CURRÍCULO, FORMAÇÃO E PRÁTICAS DE ENSINO}

\begin{abstract}
Resumo
Este trabalho têm como objetivo propor o uso de Tecnologias 3D no ensino da cartografia e geomorfologia, para isto foi utilizada uma Impressora 3D, modelo RepRap Mendel Prusa V2, construída no Campus da UFRRJ, para a impressão de feições geomorfológicas capazes de proporcionar um ensino com base em modelos físicos com base construtivista. A metodologia utilizou dados cartográficos extraídos de hipsometria da morfologia do Pão de Açúcar que resultaram em um MDE que foi impresso em partes para desenvolvimento de atividades para compreensão de curvas de nível e variáveis geomorfológicas do relevo. Os resultados demonstram a possibilidade de aplicação em escolas atendidas pelo PIBID Geografia UFRRJ no município de Seropédica/RJ.
\end{abstract}

Palavras chave: Ensino Didático; Impressora 3D; Geomorfologia;

\section{Introdução}

A compreensão da realidade geográfica é de suma importância para o aluno e torna possível o estudo de diferentes questões que visam a construção de uma visão mais crítica da realidade (CALLAI, 2000). Nessa linha de pensamento, a produção de materiais didáticos, como é o caso das maquetes, auxilia os professores na organização de atividades de ensino visando uma maior interação e pensamento dos alunos durante as aulas, de forma dinâmica e participativa (BOTELHO, 2005).

Castrogiovanni (2000) define a maquete como um modelo tridimensional de espaço; é como um laboratório geográfico, onde as interações sociais do aluno, no seu dia a dia, são passíveis de serem percebidas, quase que na sua totalidade. A construção da maquete é um dos primeiros passos para um trabalho mais sistemático das representações geográficas, tornando sua utilização, no auxílio ao ensino, uma técnica muito importante e boa para a compreensão do mundo geográfico.

A construção de maquetes topográficas pode trazer os conhecimentos de comunicação cartográfica e representações do relevo para os alunos do Ensino Básico. Esses conhecimentos devem ser embasados através da apresentação de uma alfabetização cartográfica consistente em que, segundo Castelar 
OS DESAFIOS DA GEOGRAFIA FÍSICA NA FRONTEIRA DO CONHECIMENTO

Instituto de Geociências - Unicamp

Campinas - SP

28 de Junho à 02 de Julho de 2017

(2000), a criança reconhece os lugares, conseguindo identificar as paisagens. Esse estímulo amplia o olhar sobre o espaço e auxilia o reconhecimento de si fazendo a identificação da criança como ser social (CAMPOS et al., 2009).

Conjuntamente com a Cartografia, as maquetes possibilitam também a observação das representações do relevo que são objeto de estudo da Geomorfologia. A superfície terrestre se caracteriza por elevações e depressões que constituem o relevo terrestre, cujas macroformas são descritas por denominações convencionais como depressões, planícies, planaltos e montanhas (FLORENZANO, 2008).

Para que esses entendimentos sejam concretizados, é importante relacionar a construção de maquetes por meio de impressora 3D através da inserção desses resultados no contexto do ensino da Geografia Física visando o aprimoramento e inovação do Ensino que se torna um desafio diário para os professores. Gomes et al (2005) relata que a produção de material didático deveria fazer parte da formação dos professores de Geografia. Todavia, por diversos motivos, como: tempo, disponibilidade de recursos, laboratório apropriado, entre outros, esta formação não ocorre. Há apenas informação sobre a possibilidade e a facilidade do seu emprego na sala de aula.

Como objeto de estudo, foi escolhida a impressão da forma geomorfológica do Pão de Açúcar que se trata de um símbolo conhecido mundialmente e de cunho geomorfológico acessível. Os dados foram coletados através de cartas topográficas que foram editadas em programas de SIG e impressão 3D.

\section{Impressora 3D}

Neste estudo foi utilizada a Impressora 3D RepRap, modelo Prusa Mendel V2 de baixo custo, desenvolvida no Campus da Universidade Federal Rural do Rio de Janeiro - UFRRJ, que visa auxiliar a construção da aprendizagem partindo do abstrato para o concreto a partir da construção de curvas de nível. Os modelos 3D são construídos a partir de diversos softwares como AutoCad, Google SketchUp, Zmodeler, Art Of Ilusion, além de digitalizadores a laser e com luz estruturada, que é uma tecnologia de medição e digitalização 3D de alta precisão. Portanto, as imagens podem ser construídas por softwares e/ou pelos digitalizadores. É relevante ressaltar, que o uso das impressoras 3D está cada vez mais ganhando espaço nos campos de pesquisas, sendo utilizados para amplas finalidades, até mesmo produzindo próteses para o corpo humano. Logo, já existe considerável conhecimento para se alcançar cada vez mais as representações do objeto que existem no mundo real.

Estas ferramentas se caracterizam por trabalhar com base no sistema cartesiano x, y e z; a impressão se inseriu nas dimensões de $20 \mathrm{~cm} \times 20 \mathrm{~cm} \times 8 \mathrm{~cm}$; o filamento utilizado foi o ABS (Acrilonitrila Butadieno Estireno) que deve ser aquecido acima de $210^{\circ} \mathrm{C}$; a arte foi produzida segundo o que se conhece por "arte à prova d' água" e; por fim, o diâmetro de saída do hotend, ou bico de saída, foi de 
XVII Simpósio Brasileiro

de Geografia Fisica Aplicada

I Congresso Nacional

de Geografia Física

\section{OS DESAFIOS DA GEOGRAFIA FÍSICA NA FRONTEIRA DO CONHECIMENTO \\ Instituto de Geociências - Unicamp \\ Campinas - SP \\ 28 de Junho à 02 de Julho de 2017}

0,4 mm, sendo que os diâmetros variam de $0,1 \mathrm{~mm}$ a mais de $1.0 \mathrm{~mm}$, o que permite inferir na qualidade e no tempo que um objeto deve ser impresso.

\section{Metodologia}

A metodologia utilizou dados de base cartográfica na escala 1:10.000 desenvolvidos pelo Instituto Pereira Passos (IPP) em que foram extraídas e editadas curvas de nível em equidistância de 5 metros, pontos cotados e hidrografia. Segue abaixo as etapas realizadas e efetuadas dentro da metodologia (Figura 1):

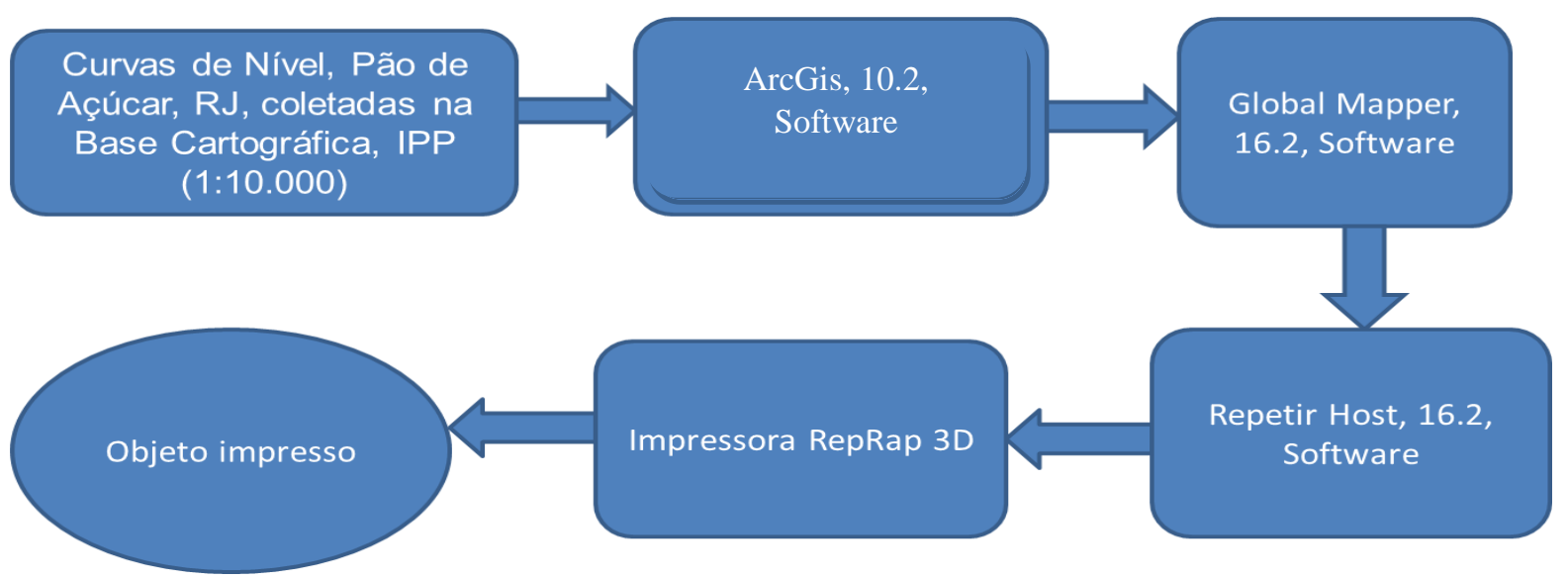

Figura 1 - Fluxograma metodológico

A base cartográfica foi editada no ArcGIS 10.2 e resultou na construção de um Modelo Digital de Elevação (MDE) em formato TIFF. O MDE foi inserido no Global Mapper 16.2 para realização de conversão em formato STL, que se trata de um tipo de arquivo universal para impressão 3D.

Visando a abordagem da utilização de curvas de nível para o ensino didático optou-se por dividir o objeto impresso em partes. Neste estudo, foi decidida a escolha da divisão em cinco partes, ou níveis, entretanto, é possível dividir em menos ou em mais níveis, o limite de divisão varia de acordo com o tamanho e a espessura desejada da impressão e a relação com os níveis da elevação real do objeto.

A obtenção da forma do Pão de Açúcar impressa em 3D proporciona a observação e descrição de algumas variáveis geomorfológicas como declividade e forma das encostas além da posição das vertentes que podem propiciar no ensino de Geografia o desenvolvimento de diversas atividades que abordam a elaboração de mapas topográficos e os seus efeitos na transformação da paisagem (Figura 2). 


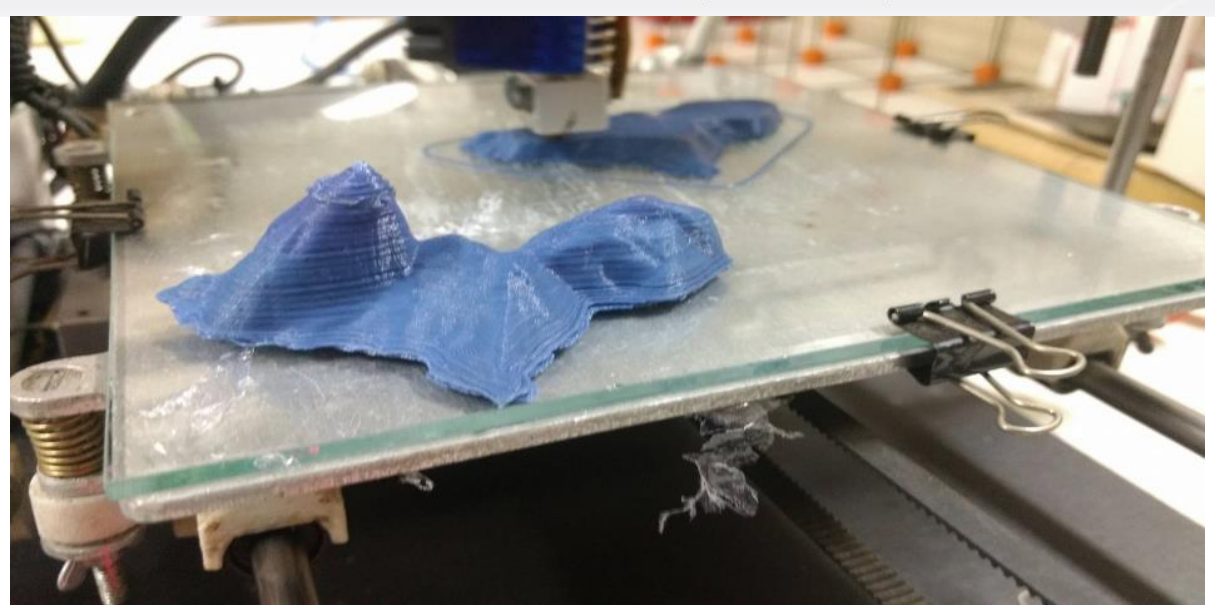

Figura 2 - Pão de Açúcar gerado por impressão 3D.

\section{Conclusão}

Acredita-se que o uso dessa tecnologia possa dar mais materialidade a alguns conceitos dentro dos estudos cartográficos e geomorfológicos propiciando dessa forma uma melhor compreensão de representação das características da natureza por meio da transformação do que é abstrato para o concreto.

A utilização da impressora 3D para construção do modelo 3D Pão de Açúcar abre caminho para a elaboração de outros exemplos geomorfológicos que podem propiciar melhor entendimento das diferentes formas de relevo. O exercício de construção das curvas de nível através do modelo do Pão de Açúcar pode melhorar o entendimento do significado geomorfológico. Isso é importante porque pode reduzir ou eliminar dúvidas apresentadas pelos alunos no ensino básico de Geografia.

Pretende-se aplicar e desenvolver esses resultados nas escolas que participam do PIBID Geografia que é realizado pelo curso de Geografia da Universidade Federal Rural do Rio de Janeiro no município de Seropédica/RJ.

\section{Bibliografia}

BOTELHO L.A.I., SILVEIRA J.S., ANDRADE S.N. Belo Horizonte, Cadernos de geografia, 25(15):60-76. $2^{\circ}$ semestre 2005.

CALLAI H.C. O ensino de geografia: recortes espaciais para análise. In: CASTROGIOVANNI A.C., CALLAI H.C., SCHAFFER N.O., KAERCHER N.A. (Orgs.). Geografia em sala de aula, práticas e reflexões. $4^{\text {a }}$ ed. Porto Alegre: Mediação p. 57-63, 2003.

CAMPOS, S.B.; OLIVEIRA, K.N.; NOGUEIRA, R.E. Oficinas, espaço do saber: construindo conceitos do relevo terrestre. In.: NOGUEIRA, R.E. (Org.) Motivações hodiernas para ensinar Geografia: Representações do espaço para visuais e invisuais. Florianópolis: Ed. da Autora, 2009. p. 15-26.

CASTELLAR, S.M.V. Educação geográfica: a psicogenética e o conhecimento escolar. Cadernos CEDES, Campinas, v. 25, n. 66, p. 209-225, maio/ago. 2005.

CASTROGIOVANNI A.C. (Org.). Ensino de geografia: práticas e textualizações no cotidiano. Porto Alegre: Mediação, 2000.

GOMES. F. L. et al. Em prol do ensino de geografia: projetos desenvolvidos no Legeo-UFU. In: Encontro De Geógrafos Da América Latina, 10., 2005, São Paulo. Anais... São Paulo: AGB, 2005. 